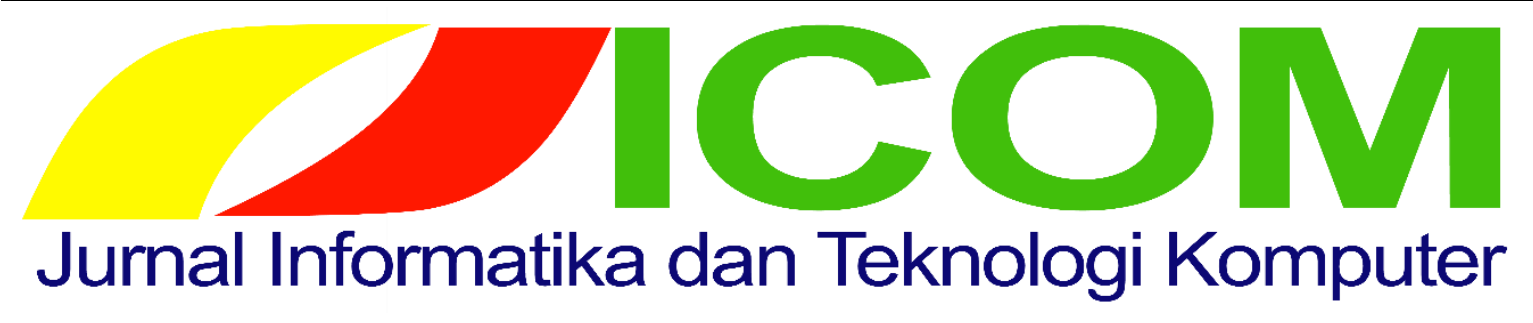

Vol. 02 No. 01 (2021) 29 - 36

E-ISSN :2774-7115 P-ISSN: 2775-2089

\title{
PENGADUAN MASYARAKAT BERBASIS ANDROID (STUDI KASUS PERUSAHAAN DAERAH AIR MINUM (PDAM) KOTA LANGSA)
}

\author{
Said Deri Andika ${ }^{1}$, Dwi Rifanda ${ }^{2}$, Nurul Fadillah ${ }^{3}$ \\ Teknik Informatika, Teknik, Universitas Samudra \\ 11deri.andika35@gmail.com, ${ }^{2}$ dwirifanda@gmail.com, ${ }^{3}$ nurulfadillah@unsam.ac.id
}

\begin{abstract}
With the rapid advancement of information technology, every government agency is trying to improve the quality of its services. Public complaint service is a form of participation to play a role in building and monitoring the performance of government agencies. Likewise with the Langsa Regional Drinking Water Company (PDAM) where people in the City find it difficult to convey complaints in their environment to related parties. Related to the basic needs of PDAM Kota Langsa for improving service to customers and making it easier for customers to submit complaints, a system that can send customer complaint data to the server is needed via a supporting device, namely Android mobile. big compared to storing them manually. Of course, in designing and making this application, there are several steps that need to be done, namely by understanding the current system, formulating existing problems, then designing and making a system that is able to overcome ongoing problems
\end{abstract}

Keywords: Applications, Public Complaints, Android.

\begin{abstract}
Abstrak
Dengan semakin pesatnya kemajuan teknologi informasi, setiap instansi pemerintahan berusaha dalam meningkatkan kualitas pelayanannya. Layanan pengaduan masyarakat adalah salah satu bentuk partisipasi untuk ikut berperan dalam membangun dan pengawasan terhadap kinerja instansi pemerintahan. Begitu juga dengan Perusahaan Air Minum Daerah (PDAM) Langsa dimana masyarakat di Kota tersebut sulit untuk menyampaikan keluhan yang ada dilingkungannya kepada pihak yang terkait. Terkait dengan kebutuhan mendasar dari PDAM Kota Langsa terhadap peningkatan pelayanan kepada pelanggan dan memudahkan pelanggan dalam menyampaikan pengaduan, maka diperlukannya suatu sistem yang dapat mengirim berupa data pengaduan pelanggan ke server melalui perangkat yang mendukung yaitu Android mobile. besar dibandingkan menyimpannya secara manual. Tentunya, dalam merancang dan membuat aplikasi ini, ada beberapa tahap yang perlu dilakukan,yaitu dengan memahami sistem yang sedang berjalan, merumuskan permasalahan yang ada, kemudian merancang serta membuat suatu sistem yang mampu mengatasi masalah yang sedang berlangsung
\end{abstract}

Kata kunci: Aplikasi, Pengaduan Masyarakat, Android,

\section{Pendahuluan}

Perusahaan Daerah Air Minum (PDAM) Tirta Keumuning Kota Langsa merupakan perusahaan jasa penyedia air milik Kota Langsa dengan 7.848 pelanggan yang tersebar di setiap desa yang ada di Kota Langsa. Setiap tahun pelanggan PDAM Tirta Keumuning selalu bertambah dengan berbagai macam spesifikasi jenis rumah tangga yang berbedabeda. PDAM sebagai penyedia air terbesar di Kota Langsa dengan jumlah pelanggan yang banyak tentu membuat berbagai macam permasalahan terjadi setiap hari. Gangguan pelanggan terjadi setiap hari di berbagai daerah dengan berbeda-beda Gangguan seperti pipa bocor, air macet dan lain-lain. 
Berbagai masalah gangguan yang terjadi tidak hanya pada pelanggan PDAM tetapi juga bisa terjadi pada di saluran-saluran di pingggir jalan. Gangguan yang terjadi kemudian dilaporkan oleh pelanggan atau masyarakat yang mengetahui adanya gangguan ke bagian hubungan langganan dikantor PDAM Tirta Keumuning secara langsung yang kemudian akan dilakukan pencatatan gangguan yang telah dilaporkan oleh pelanggan lalu laporan itu akan dibuatkan surat perintah perbaikan (SPT) dan diserahkan ke bagian teknik untuk kemudian akan dilakukan perencanaan perbaikan. Selain datang langsung kekantor untuk melakukan pelaporan secara manual, pelanggan yang mengalami gangguan juga dapat melaporkan gangguan melalui telepon kantor. Namun karena sumber daya manusia (SDM) memiliki kekurangan terutama dalam hal ingatan, terkadang gangguan yang dilaporkan tidak tercatat dan tidak terproses oleh petugas.

Melihat adanya kelemahan pada sistem tersebut maka solusi untuk membangun suatu sistem informasi pengaduan gangguan PDAM Tirta Keumuning berbasis android yang bisa digunakan untuk menggantikan sistem manual yang ada. Aplikasi Pengaduan Masyarakat Berbasis Android, yang dapat diakses melalui smartphone oleh pelanggan yang kemudian data yang dikirim oleh pelanggan akan masuk ke komputer admin hubungan langganan yang kemudian akan dilakukan transaksi dan data dikirim ke komputer bagian teknik untuk dilakukan perencanaan perbaikan. Data yang masuk melalui sistem ini, akan diperiksa kembali oleh petugas kebenarannya agar tidak terjadi kesalahpahaman. Setelah data diketahui akurat, maka data tersebut akan diproses sesuai sistem yang berjalan agar dapat ditindak lanjuti oleh bagian teknik untuk melakukan perbaikan. Diharapkan dengan adanya sistem ini dapat membantu pelanggan untuk melaporkan gangguan tanpa harus datang kekantor dan memudahkan admin hubungan langganan untuk melakukan transaksi dengan bagian admin teknik.

\section{Rancangan Sistem dan Analisis}

\subsection{Analisis Sistem}

Analisis sistem merupakan penguraian dari suatu sistem yang utuh ke dalam bagian-bagian komponennya untuk mengidentifikasi dan mengevaluasi permasalahan. Dari proses yang berjalan sebelumnya akan dikembangkan sebuah aplikasi mobile yang dapat mempermudah pihak masyarakat Kota Langsa dalam mengadukan adanya gangguan kerusakan di daerah Kota Langsa Berikut adalah rancangan analisis sistem tersebut.

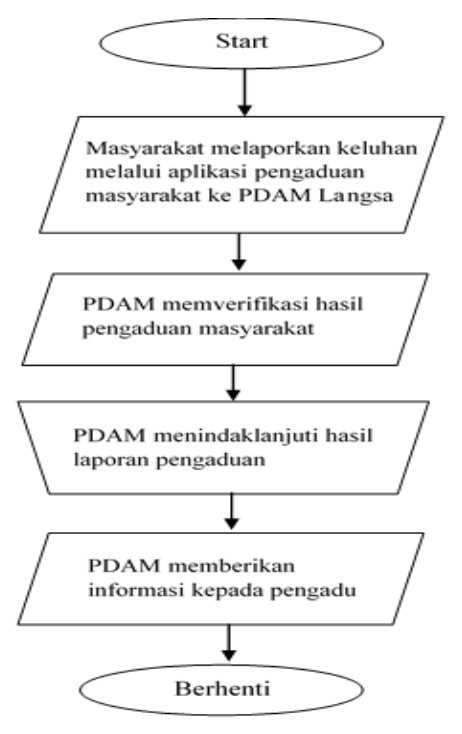

Gambar 1. Flow Map Diagram Sistem.

Sistem diatas tersebut yang diusulkan masyarakat melakukan pengaduan melalui smartphone yang kemudian data yang dikirim oleh pelanggan akan masuk ke komputer admin hubungan langganan yang kemudian akan dilakukan transaksi dan data dikirim ke komputer bagian teknik untuk dilakukan perencanaan perbaikan. Data yang masuk melalui sistem ini, akan diperiksa kembali oleh petugas kebenarannya agar tidak terjadi kesalahpahaman. Setelah data diketahui akurat, maka data tersebut akan diproses sesuaisistem yang berjalan agar dapat ditindak lanjuti oleh bagian teknik untuk melakukan perbaikan.

\subsubsection{Analisis Masalah}

Masyarakat Kota Langsa selama terbentuknya Perusahaan Daerah Air Minum (PAM) hingga saat ini masih mengandalkan penerimaan pelaporan dan pengaduan yang dilakukan oleh masyarakat terhadap bentukbentuk pelayananpublik masih bersifat manual. Artinya Masyarakat dalam hal ini harus datang secara langsung kepada Perusahaan Daerah Air Minum (PDAM) Kota Langsa. Ini menunjukkan belum terciptanya palayanan publik yang efektif dan efisien dengan asas cepat, tepat dan biaya murah. Jadi perlu dibuatkan aplikasi pelaporan pelayanan publik yangdapat membantu masyarakat untuk melaporkan pelanggaran-pelanggaran hukum dan ketidakpuasan pelayanan publik oleh Perusahaan Daerah Air Minum (PDAM) Kota Langsa.

\subsubsection{Analisis Kebutuhan Sistem}

a. Kebutuhan Antarmuka (Interface) Kebutuhan-kebutuhan antarmuka untuk pembangunan aplikasi ini yaitu sebagai berikut: 
1) Aplikasi yang dibangun akan mempunyai antarmuka yang familiar dan mudah digunakan bagi pengguna.

2) Aplikasi menampilkan halaman sistem untuk melakukan login.

3) Aplikasi menampilkan halaman sistem untuk melaporkan pelanggaran pelayanan public

b. Kebutuhan Data

Data yang diolah oleh sistem ini yaitu sebagai berikut:

1) Data Pelapor

2) Data laporan

\section{c. Kebutuhan Fungsional}

Kebutuhan fungsional merupakan penjelasan proses fungsi yang berupa penjelasan secara terinci setiap fungsi yang digunakan untuk menyelesaikan masalah.

1) Fungsi-fungsi yang dimiliki oleh aplikasi ini adalah sebagai berikut:

Melakukan registrasi akun pelapor.

2) Melakukan pelaporan pelanggaran pelayanan publik. bertidak sebagai user untuk Aplikasi Pengaduan Masyarakat. Adapun pengguna sebagai aktor dapat mengakses semua fitur pada aplikasi dengan kata lain masing-masing use case yang terhubung dengan pengguna dapat langsung diakses oleh pengguna.

1. Pada Gambar 2 diatas terdapat 1 aktor yaitu user dan beberapa use case yang diantaranya adalah : Registrasi, pada use case ini aktor atau pengguna dapat melakukan registrasi pengguna dengan memasukkan data diri yang kemudian nantinya akan tersimpan dalam database.

2. Melakukan login, pada use case ini pengguna dapat masuk ke aplikasi melalui login dengan username dan password yang sudah terdaftar.

3. Membuka menu home, pada use case ini pengguna dapat memilih beberapa pilihan menu yang ada di menu home.

4. Membuka tentang, pada use case ini pengguna dapat terbantu dalam melakukan pengaduan adanya informasi tentang pengaduan.

5. Menu pelaporan, pada use case ini pengguna dapat memilih beberapa objek gangguan yang terdapat diaplikasi.

6. Membuat laporan, pada use case ini pengguna dapat melakukkan pengaduan setelah memilih objek gangguan dan memasukkan keterangan gangguan.

\subsubsection{Class Diagram}

Class Diagram merupakan diagram yang menggambarkan struktur sistem dari segi pendefinisian kelas-kelas yang akan dibuat untuk membangun sistem.

Class diagram membantu kita dalam visualisasi struktur kelas-kelas Dari suatu sistem dan merupakan tipe diagram yang paling banyak dipakai. Class diagram memperlihatkan hubungan antar kelas dan penjelasan detail tiap-tiap kelas didalam model desain dari suatu sistem, seperti Gambar berikut ini: 


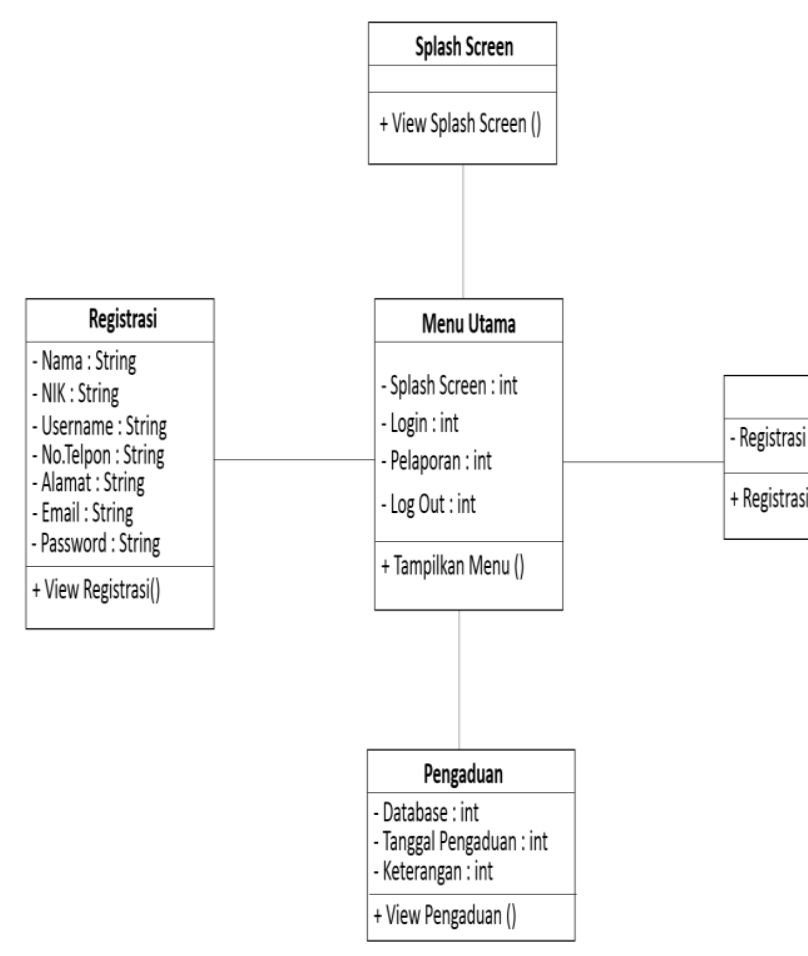

. Gambar 3. Class Diagram

Pada bagian ini akan dibuat sebuah class diagram untuk menggambarkan class-class yang perlu dibuat dalam perancangan aplikasi. Di sini terdapat 5 class yaitu Menu Utama, Splashscreen, Login, Registrasi, dan pengaduan. Class Menu Utama digunakan untuk menyusun menu utama aplikasi. Class Splashscreen digunakan untuk menampilkan tampilan awal aplikasi pengaduan masyarakat. Class login digunakan memulai dan masuk aplikasi. Class registrasi digunakan untuk memasukkan data diri dan kemudian di simpan di database. Class pengaduan untuk menginputkan pengaduan berdasarkan gangguan dan menyimpan data jenis pengaduan.

\subsubsection{Sequence Diagram}

Sequence diagram menggambarkan interaksi antar objek di dalam dan di sekitar sistem berupa message terhadap waktu. Pembuatan sequence diagram bertujuan agar perancangan aplikasi lebih mudah dan terarah. Interaksiinteraksi yang terjadi dallam aplikasi adalah :

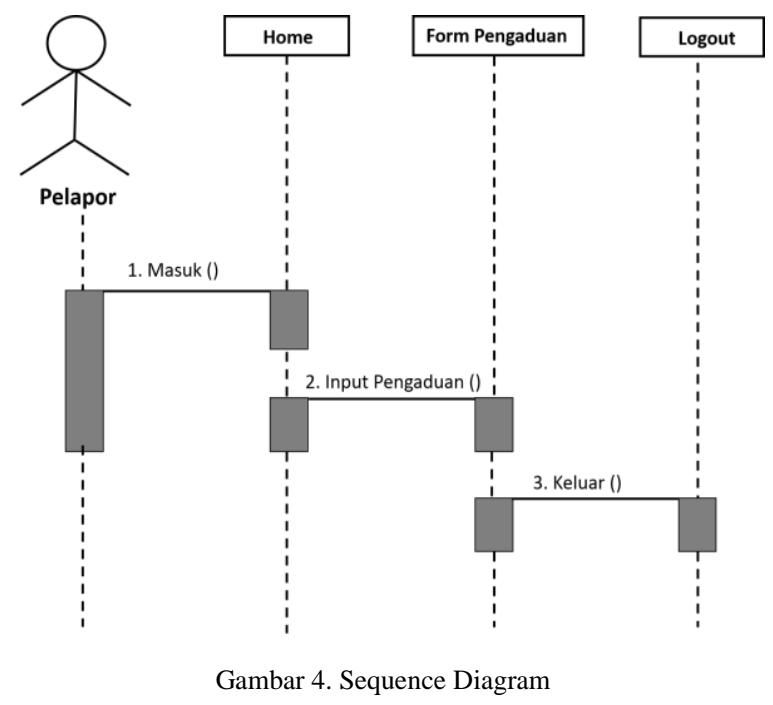

Proses pada gambar 4 dimulai pada saat pengguna membuka aplikasi Pengaduan masyarakat kemudian pengguna akan masuk melalui login kemudian sistem akan memuat daftar pengguna yang telah ada apabila pengguna tidak terdaftar pengguna dapat melakukan daftar pengguna baru untuk dapat mengakses aplikasi. Sedangkan apabila pengguna telah terdaftar, pengguna tinggal memasukkan nama pengguna kemudian sistem akan mengirim nama pengguna pada Database. Kemudian pengguna melakukan penginputan pengaduan direspon sistem dengan menampilkan beberapa objek gangguan. Kemudian untuk mengganti akun pengguna dapat memilih menu logout dan kemudian apliaksi akan menampilkan halaman menu login kembali, dan pengguna dapat melakukan login dengan akun yang terdataftar lainnya.

\subsubsection{Flowchart (Alur Sistem)}

Flowchart atau Bagan alir adalah bagan (chart) yang menunjukkan alir (flow) di dalam program atau prosedur sistem secara logika. Bagan alir (flowchart) digunakan terutama untuk alat bantu komunikasi dan untuk dokumentasi.

Sistem flowchart adalah urutan proses dalam sistem dengan menunjukan alat media input, output serta jenis media penyimpanan dalam proses pengolahan data. Program flowchart adalah suatu bagan dengan simbol simbol tertentuBerikut adalah flowchart dari Sistem yang menggambarkan urutan proses secara mendetail dan hubungan antara suatu proses (instruksi) dengan proses lainnya dalam suatu program. Berikut adalah flowchart dari sistem. 


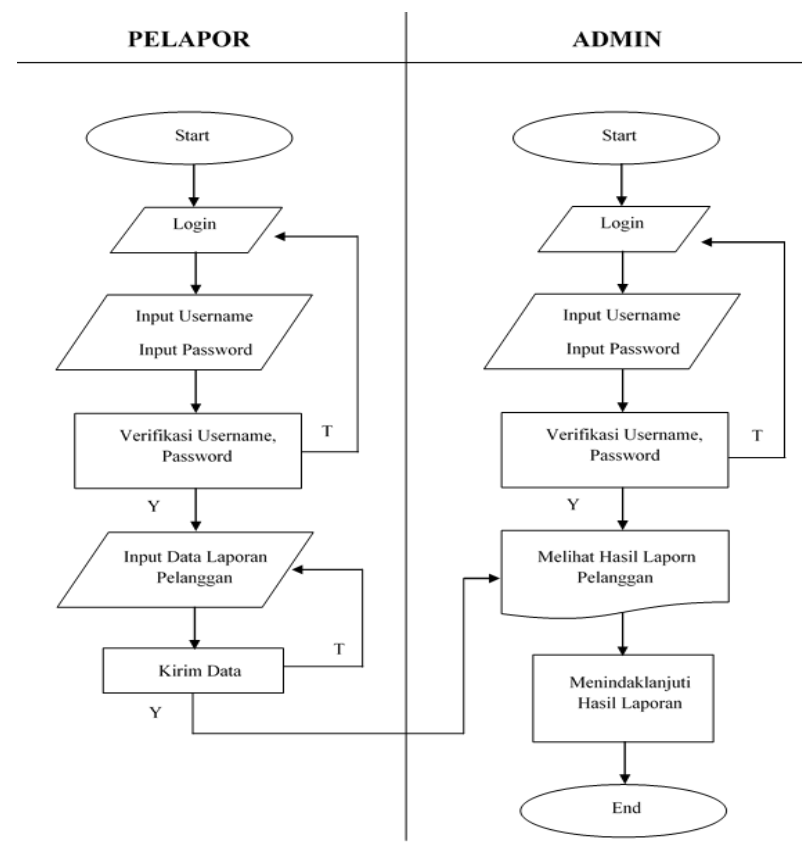

Gambar 5. Flowchart (Alur Sistem)

Pada perancangan flowchart, pelapor harus menginput username dan password yang kemudian di verifikasi apabila username dan password sudah benar maka pelapor atau user bisa melaporkan kejadian pelanggaran yang ditemui dan mengirim semua data yang dibutuhkan dalam laporan, kemudian data laporan dari user akan ditindak lanjuti oleh pihak PDAM.

\subsubsection{Perancangan Sistem}

Untuk menjelaskan perancangan sistem yang dilakukan dalam mewujudkan penelitian sistem pelaporan pelayanan publik berbasis android. Terlebih dahulu secara umum digambarkan oleh blok diagram cara kerja yang ditunjukkan masyarakat sebagai pelapor pelanggaran pelayanan publik, kemudian masyarakat melakukan pelaporan melalui aplikasi pelaporan ini dan dikirim ke kantor PDAM Tirta Keumuning Kota Langsa. Adapun rancangan blok diagram sistem pelaporan pelayanan publik berbasis android yang akan di buat adalah sebagai berikut seperti pada gambar 6 .

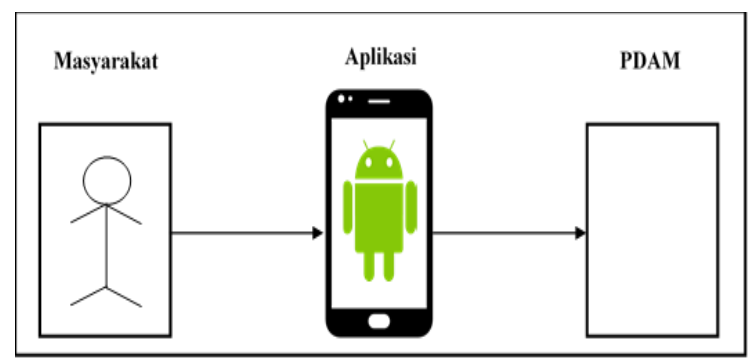

Gambar 6. Desain Keseluruhan Sistem

Masyarakat berperan sebagai pelapor pelayanan publik melalui media smartphone android dengan aplikasi pelaporan pelayanan publik ini, kemudian akan di teruskan ke kantor PDAM Kota Langsa untuk melakukan verifikasi dan menindaklanjuti masalah yang dilaporkan.

\section{Hasil dan Pembahasan}

Implementasi merupakan tahap akhir dalam pembangunan sistem, yang diamana pada tahap ini sistem akan diimplementasikan. Adapun hasil dari implementasi sistem yaitu sbeagai berikut.

\subsection{Antarmuka Splashscreen}

Antarmuka splash screen akan menampilkan gambar splash screen aplikasi selama 3 detik. Setelah 3 detik akan muncul antarmuka menu utama.Berikut gambar dari antarmuka splashscreen aplikasi.

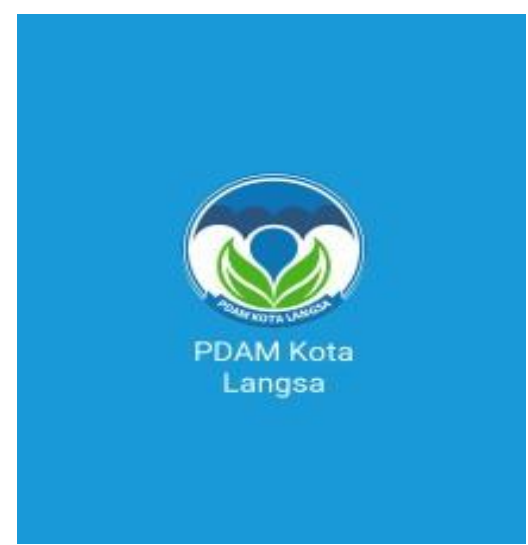

Gambar 7 Antarmuka Splashscreen

\subsection{Antarmuka Login}

Antarmuka Login akan muncul ketika antarmuka splash screen telah selesai tampil. Halaman Login merupakan halaman yang digunakan oleh pengguna yang sudah memiliki akun pelapor dan yang sudah terdaftar untuk dapat masuk ke aplikasi sistem pengaduan. Pada halaman login Pengguna akan diminta untuk mengisi form login yang sudah disediakan berupa username dan password yang dibuat pengguna saat melakukan registrasi. Berikut gambar dari antarmuka Login

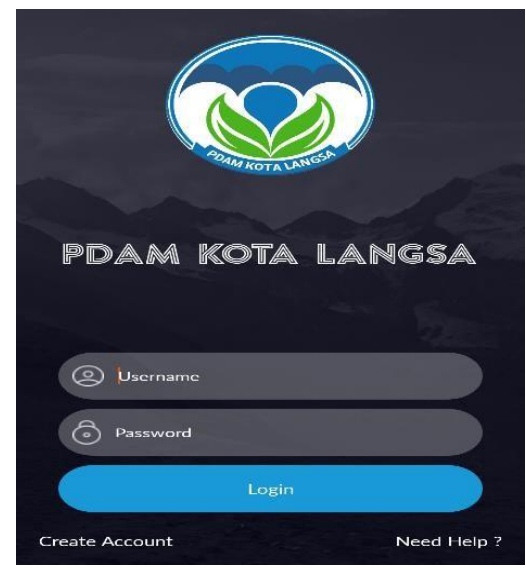

Gambar 8 Antarmuka Login 
Setelah semua data diisi, pengguna mengklik tombol login. Selanjutnya sistem akan melakukan pengecekan terhadap data yang sudah di input oleh pelapor dan mencocokkannya dengan data pada tabel user yang ada di database server. Apabila data yang di input sesuai maka pelapor akan diarahkan kehalaman input data pengaduan, jika ada yang berbeda maka akan muncul pesan eror dan meminta pelapor untuk melakukan login kembali.

\subsection{Antarmuka Menu Home}

Antarmuka menu home akan muncul ketika Login username dan password terkonfirmasi dengan benar. Halaman home merupakan halaman yang pertama kali dilihat oleh admin dan penindak saat mengakses sistem.Berikut gambar dari antarmuka menu home.

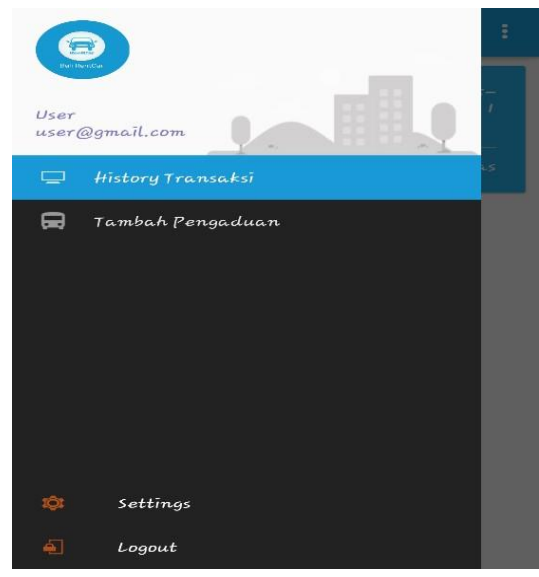

Gambar 9 Antarmuka Menu Home

Pada halaman home terdapat beberapa menu, yaitu: Menu History, menu Tambah pengaduan, menu setting, dan menu logout. Menu history adalah menu untuk menampilkan history pengaduan yang sudah di verifikasi atau belum oleh admin. Menu tambah pengaduan adalah menu untuk menampilkan penambahan jika ada gangguan lain yang terjadi maka user bisa melakukan penambahan pengaduan. Menu setting dapat digunakan untuk melakukan pengeditan data user. Dan menu log out digunakan jika user ingin mengganti akun dan melakukan login ulang.

\subsection{Antarmuka Item Pengaduan}

Antarmuka item pengaduan berisi data-data tentang objek gangguan pada air atau pipa dan akan melakukan pengaduan oleh user. Berikut tampilan antarmuka item pengaduan

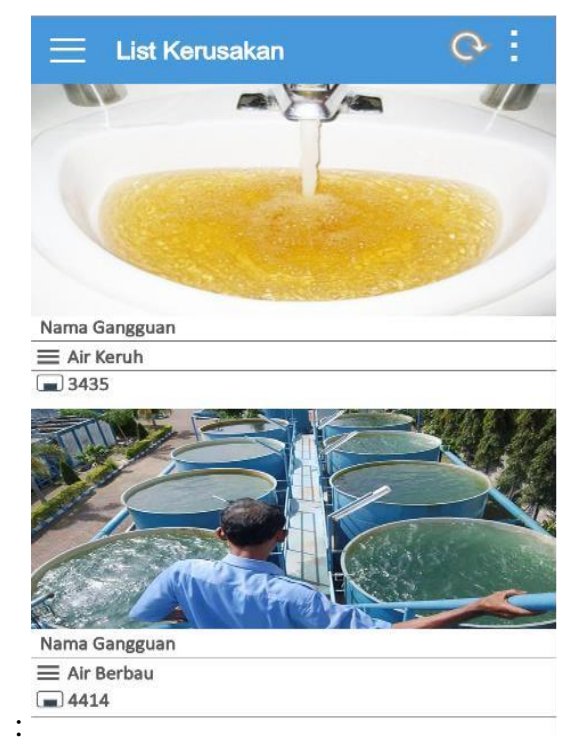

Gambar 10 Antarmuka Item Pengaduan

Pada halaman item pengaduan akan menampilkan list kerusakan yang sering terjadi di masyarakat. User dapat memilih objek gangguan sesuai dengan kejadian kerusakan yang dialami, setiap data kerusakan hanya dapat diinput melalui sistem dari admin.

\subsection{Antarmuka Item Input Pengaduan}

Antarmuka item input pengaduan berisi data-data tentang objek gangguan pada air atau pipa dan memasukkan tanggal pengaduan dan keterangan gangguan yang ingin diadukan akan melakukan pengaduan oleh user. Berikut tampilan antarmuka item input pengaduan :

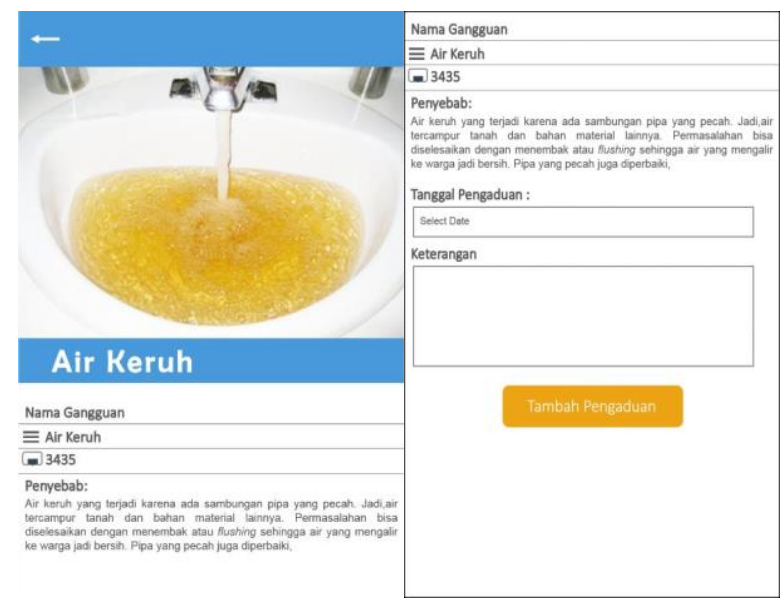

Gambar 11 Antarmuka Item Input Pengaduan

Pada halaman item input pengaduan akan menampilkan objek gangguan yang dipilih user. Setiap objek yang sudah dipilih oleh user aplikasi akan menampilkan gambar, nama, dan id dari objek gangguan tersebut. Setelah memilih objek gangguan selanjutnya memasukkan tanggal saat gangguan itu terjadi, dan kemudian memasukkan keterangan dan 
penjelasan tentang gangguan yang terjadi. Selanjutnya menekan tombol tambah pengaduan, maka data akan terkirim ke admin dan tunggu pihak admin memverifikasi hasil laporan

\subsection{Antarmuka Item Profil}

Antarmuka item profil berisi data-data tentang user. Berikut tampilam antarmuka item profil :

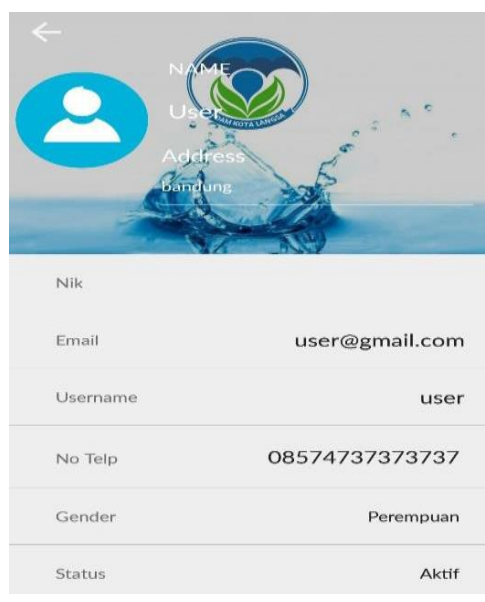

Gambar 12 Antarmuka Item Profil

Pada halaman item profil disini akan menampilkan data diri user yang terdiri atas Nomor induk kependudukan, Nama, Username, Nomor telepon, Gender, dan Status aktif jika sudah terdaftar pada PDAM tersebut

\subsection{Antarmuka Item Edit Profil}

Antarmuka item edit profil berisi data-data perubahan tentang user. Berikut tampilam antarmuka item edit profil :

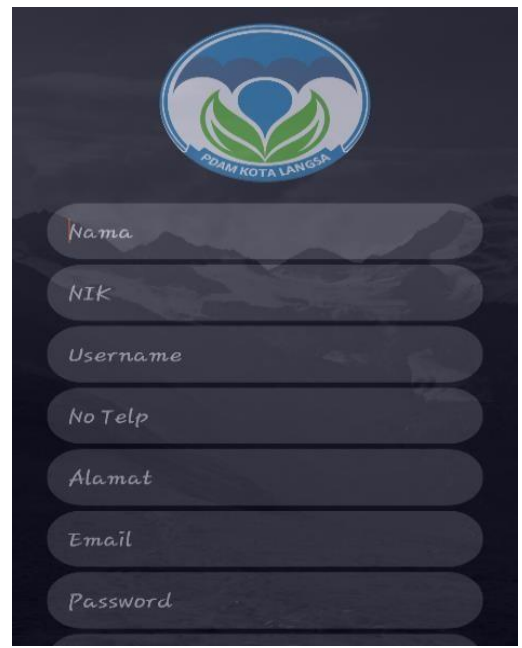

Gambar 13 Antarmuka Edit Profil

Pada halaman item Edit profil disini user dapat mengedit data diri baik mengubah Nomor induk kependudukan, Nama, Username, Nomor telepon,
Email, dan Password yang diinginkan yang nantinya data akan masuk ke sistem admin.

\subsection{Antarmuka Item History Pengaduan}

Antarmuka ini berisi data-data pengaduan dari user yang menunggu konfirmasi dari admin.Berikut tampilan dari antarmuka History Pengaduan:

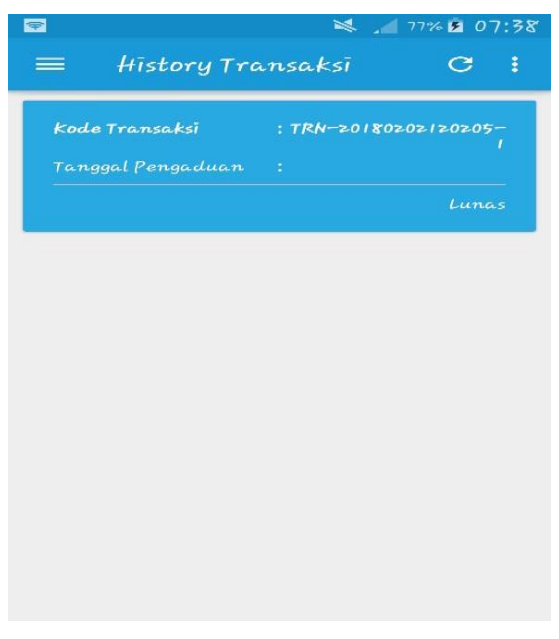

Gambar 14 Antarmuka History Pengaduan

Pada halaman History pengaduan akan menampilkan data hasil pengaduan yang dilakukan user yang nantinya user menunggu hasil verifikasi dari admin pihhak PDAM Tirta Keumuning.

\subsection{Antarmuka Item Data Pengaduan Telah Di Verifikasi}

Antarmuka ini berisi data-data pengaduan dari user yang telah diverifikasi oleh admin. Jika sudah diverifikasi maka Form akan berubah menjadi biru, jika belum diverifikasi maka form berwarna merah. Berikut tampilan dari antarmuka Data pengaduan yang telah diverifikasi:

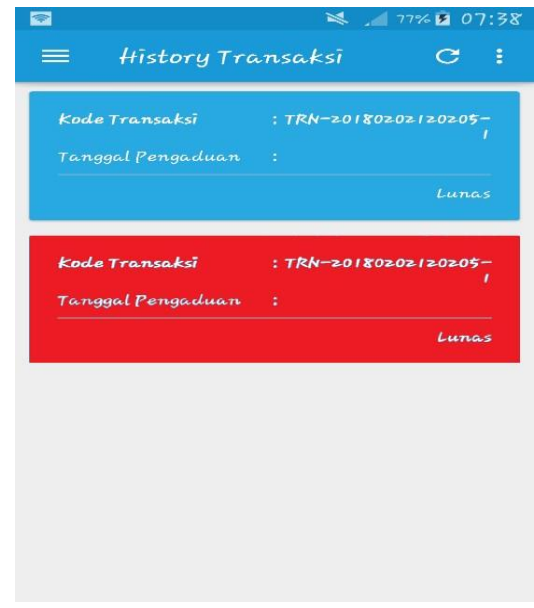

Gambar 15 Antarmuka Item data pengaduan telah diverifikasi

Pada halaman verifikasi pengaduan menampilkan Proses verifikasi pengaduan yang dijalankan sistem 
adalah dengan mengubah status pengaduan pada history pengaduan. Jika pengaduan yang sudah dikirim maka pada history pengaduan akan memunculkan data transaksi berwarna merah, dan jika pengaduan yang sudah dikirim dan sudah ditindak lanjuti maka tapilan data transaksi akan berubah menjadi warna biru yang berarti telah di verifikasi dan di tindak lanjuti

\section{Kesimpulan}

Setelah pembuatan Aplikasi Pengaduan Masyarakat Berbasis Android Pada PDAM Tirta Keumeuneng Kota Langsa maka dapat ditarik kesimpulan bahwa:

1 Aplikasi ini dapat menggantikan dan pilihan alternatif pelayanan call center 24 jam pada PDAM Tirta Keumeuneng Kota Langsa .

2 Aplikasi ini dapat memberikan wadah dan fasilitas pada aplikasi mobile untuk pengaduan masyarakat tentang gangguan-gangguan guna membantu masyarakat untuk menyampaikan keluhan pada PDAM Tirta Keumeuneng Kota Langsa .

3 Dengan dibuatnya aplikasi pengaduan berbasis android ini akan akan meminimalisir waktu yang terpakai bagi masyarakat yang jauh dari kantor PDAM Tirta Keumuning Kota Langsa. Dan juga meminimalisirkan waktu pelayanan pihak PDAM yang biasanya melayani dan menyelesaikan 3-4 keluhan dalam sehari menjadi satu keluhan selesai dalam waktu 5-6 jam.

\section{Daftar Pustaka}

[1] Dai.R.H, Hadjaratic. L, Bouti. N.F , "Rancang bangun aplikasi E-Report Pengaduan Masyarakat Design Public Complaint E-Report Application" (2015).64-73

[2] Lengkong, H.N, Sinsuw, A.A.E, Lumenta, A.S.M "Perancangan Penunjuk Rute Pada Kendaraan Pribadi Menggunakan Aplikasi Mobile GIS Berbasis Android Yang Terintegrasi Pada Google Maps", E-journal Teknik Elektro dan Komputer, UNSRAT, (2015). 18-25

[3] Eriyani. F, Priyambadha. B, Nurwasito. H, "Pengembangan Aplikasi Mobile Pengaduan Masyarakat Pada Dinas Perhubungan Kota Malang Menggunakan Fitur Location Based Service Berbasis Android”, Jurnal Pengembangan Teknnologi Informasi dan Ilmu Komputer,Universitas Brawijya. (2019).40834091.

[4] Tresnawati. D, Hidayat. E, "Pengembangan Aplikasi Mobile Pengaduan Masyarakat Pada Dinas Perhubungan Kota Malang Menggunakan Fitur Location Based Service Berbasis Android" Jurnal Algoritma..Sekolah Tinnggi Garut. (2017). 400-409

[5] Ramanda. K, "PENERAPAN SISTEM MANAJEMEN OPERASIONAL PELAYANAN PEMESANAN MENU MAKANAN DENGAN WAITING LINE METHOD," Jurnal Pilar Nusa Mandiri., vol. XII, no. 2, 2016. 182-189. 